\title{
Affirmative Action in College Admissions: A Compelling Need and a Compelling Warning
}

\section{Scott Finnie \\ Eastern Washington University}

Introduction: Higher education has been historically recognized as the very door to opportunity and success for our nation's youths and future leaders. Following the civil rights movement of the 1950s and 1960s, the cry and pressure for access to America's college campuses have intensified, especially along the lines of racial and gender discrimination. The long record of oppression has translated into an intense debate over the feasibility of affirmative action as a viable policy to rectify the past and the present. This article will afford a brief overview of the necessity of affimative action in college admissions as well as an analysis and assessment of this policy from the perspective of Critical Race Theory.

\section{A Brief History-Higher Education's \\ Commitment to Preferential Admissions}

Higher education has been generally looked upon as a unique institution in American society. Historically, colleges and universities are perceived as vital instruments for improving and uplifting both the community and individual citizens. According to Lowe (1999) their capacity to provide paths to social progress and individual development are considered their most prized contributions (p. 17). He further maintains that

Academic culture is driven by a peculiar combination of individualism and social purpose. On the one hand, it exalts a kind of maximization of individual development and choice; on the other, it appropriately justifies its efforts in a discourse based on public mission and the common good. ... The escalating influence of government in higher education supported the mix of individualistic maximization and the social purpose that has become characteristic of the ethos of American higher education. (p. 18)

Lowe further asscrts that with the social changes brought in by the civil rights movement of the 1950s and 1960s, higher education's role as a leading agent of collective and individual reform was amplified. Thus, racial inclusion becarne a top priority for one of the nation's highest profile institutions (p. 19). As a result, the social purpose of higher education inevitably converged with the intent and goal of the newly-surfaced policy of affirmative action. Because of their influence upon the minds and leaders of the future, 
colleges and universities looked upon themselves as the anticipated channel of access for minorities to help shape their newfound destiny in American society (p. 177).

This call to shape such a destiny was delivered by President Lyndon Johnson's historic speech in June of 1965 at Howard University - recognized by many as the initiation of affirmative action in higher education. Johnson called for more aggressive steps beyond the strategies of nondiscrimination already in place at that time. Modeling after the new requirements of Executive Order 11246 which mandated that federal contractors provide specific plans for diversifying their workforce, university and college administrators began to focus on reconfigured admission procedures to admit qualified, black students despite their lower test scores and grades (Bok and Bowen, 1998, pp. 5-7).

According to Eastland (1996), this move by higher education to incorporate racial preference into college admissions was by no means a response to a federal mandate or order. It was clearly an initiative conceived and developed within higher education's own jurisdiction and powers of authority (pp. $58 \& 159$ ). The adoption of this policy for minority admissions, as confirmed by Garcia (1997), would come to play a major role in enabling affimative action to leave an "indelible imprint on the university environment" throughout the nation (p. 1).

Justification for this new approach to college admissions was centered on three concepts: (a) the need to provide for a more diverse student body that would enrich the academic community multi-culturally; (b) the need to open the door to students of color for future careers as professionals in the public and private sectors; and, (c) the need to afford some form of retribution for past injustices fiom racial discrimination (Garcia, 1997, p. 7).

As a result, colleges and universities became the centerpiece for debate in light of their policies of preferential admission based on race and ethnicity. Despite the progress cited in the above paragraph, critics are adamant in pointing out their moral suspicions surrounding the process of affimative action. The contention has focused on two key themes: (a) how to pursue equity without sacrificing an expected level of excellence and (b) how to balance the demand for quality and diversity (Lowe, 1999, pp. 18-22). Because moral claims and value judgments play such a major role at the heart of both of these issues,

Colleges and universities have become a crucible in which these continuing dilemmas and aspirations vie with one another as the institutions proceed to incorporate a historically unprecedented measure of human diversity.... Institutions of higher education are people-intensive organizations. The continuing viability of the enterprise of higher education and the status of affirmative action efforts within it will depend on what people believe, and on whether those whose cooperation cannot be mandated support the view that the kind of inclusion affirmative action encourages is good for everyone. Higher education has advanced considerably the mission of providing access; this progress notwithstanding, it has also bocome a crucible in which the unresolved dilemmas of a complicated racial history continue to 
be tested. Those charged to administer - to care for and manage - our colleges and universities do indeed live out this vocation in the heat of conflicting aspirations. (p. 24)

In conclusion, Garcia (1997) defends the use of racial preference in college admissions as a means of enabling institutions of higher education to both embrace academic excellence and promote diversity (p. 6). Higher education and affirmative action, as a result, complement each other to promote the nation's need for justice and equity for all citizens:

Our colleges and universities are at the heart of the social conscience of this nation places where artificial barriers of race, religion, class, sex, sexual orientation, and language can be transcended and where we can inspire and develop leaders who will marshal a just society. Affirmative action provides the vehicle to create campuses which transcend past and present injustices. Clearly, those involved in higher education must do a better job of educating both the public and policymakers about the importance of an inclusive society, not only for the benefit of people of color, but for us all. Common sense tells us and research confirms that the economic and competitive edge of the nation depends on the availability of educational opportunities and gainful employment for every American. (p. 3)

The Compelling Need for Racal Preference in College Admissions

The first and foremost justification for affirmative action within the college admissions process is this increased access to opportunity for students of color aforementioned by Garcia. As a universal benefit to society as a whole, Feinberg (1998) concurs that a major justification for affirmative action in higher education is its potential to qualify women and people of color for managerial and professional occupations. He asserts that the direct comelation between access to higher education and white-collar jobs points to the social value of such a policy in college admissions (p. 10).

As noted by Meier, Stewart, Jr., and England (1989), numerous observations and studies have confirmed this comelation since the inception of affimative action in college admissions. Different levels of education "by themselves explain 40 percent of the wage difference between blacks and whites" - to such an extent that "the increase impact of education on black eamings [clearly] results from substantial improvements in the quality of black education;...the result is a strong relationship, with education accounting for 53 percent of the variation in income" (p. 10). Such a strong comelation betwecn income and education cannot be ignored or reasoned away so lightly. Equal access to education afforded through preferential admissions shows forth a compelling and undeniable need when considered in this context: 
If blacks are denied equal access to education, then discrimination in the job market is much easier, because blacks will lack the educational qualifications for many jobs. In such cases, an employer need not discriminate overtly; institutional use of job qualifications is sufficient to eliminate most blacks from consideration. Equalizing access to quality education means that discrimination in employment and other areas must be overt, and overt methods of discrimination are easier to document and combat. (p. 11)

The second justification, as cited by Garcia (1997), points to the policy's remedial and societal benefit: affirmative action in college admissions makes a clear statement against the discrimination policies of the past. In other words, according to Garcia, without affimative action the practice of exclusion by race could resurface, much to the disadvantage of everyone, including minorities and women. In his estimation, the injustices of the past must be proactively addressed today on college campuses in order to sustain the remedial cycle (p. 125).

Chang, Witt, Jones, and Hakuta (2003) underscore this conclusion by citing the enduring success of the 1965 Higher Education Act that financially assisted universities and colleges in fortifying the increase of minority and poor students' participation in higher education over the past four decades. Stepping back from such proactive measures would result in a tragic discounting of society's obligation to overturn the injustices of the past - with an end result that would "dramatically alter the overall level of participation of African American and Latino students" (p. 48). Laser (1999) contends that efforts to correct past wrongs stand as an obligation of any democratic nation that claims to uphold civil liberties according to the principles of justice and equality. The past record of racial discrimination in American history alone wanants some form of intervention - by either the federal government, private employers, or school administrators. Left alone, inequality will persist, as the nation's troublesome history has already proven (p. 138).

Although according to Bok and Bowen (1998) only $20-30 \%$ of all universities across the country used race in admissions by the late 1990 s (p. 15), the positive impact of reversing the past trends of discrimination were evident in the numbers alone. In 1955, for instance, African Americans constituted only $4.9 \%$ of college students between the ages of 18 and 24; yet by 1990, that percentage rose to $11.3 \%$ - more than doubling the black student population (Feinberg, 1998, p. 10). From 1960 to 1995, the percentage of black graduates between the ages of 25 and 29 almost tripled in number, rising from $5.4 \%$ to $15.4 \%$ (Bok and Bowen, 1998, p. 9). Again, the case for affirmative action in college admissions bears compelling evidence in its defense.

The third justification points to the pressing need to address the present-day forces of institutional racism. Chang, Witt, Jones, and Hakuta (2003) contend that our nation's lengthy history of discrimination based on skin color has allowed racism to be entrenched and embedded into the very fibers of society's most basic institutions: 
The centuries of racism in this country have left a powerful legacy that permeates all levels of American life and that cannot, and should not, be ignored. Social science evidence belies the idealistic perception of the post-Civil Rights era that Americans are able to judge people solely on the basis of character. More likely, we live our whole lives operating within the societal constraints of our gender, class, and race. To accurately assess the efficacy of affimmative action, we must understand the true effects of racism on all sectors of socicty. (p. 17)

These "societal constraints" constitute a wall of disadvantage upheld by faceless, institutional racism that routinely confronts and banicades people of color, especially in the area of access to higher education and economic opportunity.

The disparity among white and black job applicants, often determined by educational opportunities among other things, serves as a glaring example of the institutional bias of today. The findings in a recent study conclude that whites obtain interviews at a $22 \%$ higher rate than blacks and are offered jobs at the interview stage at a $415 \%$ higher rate. Upon being offered the job, whites have a $17 \%$ chance of being offered a higher salary (for the same position) and are granted access to additional job vacancies at a $48 \%$ rate higher than their black counterparts (Chang, Witt, Jones, and Hakuta, 2003, p. 103). In light of such findings, some form of racial consideration in the college admissions process deems imperative as an initial response to combat racism at this institutional level:

When institutional practices or policies systematically create disadvantage for racial minority groups and their members, it doesn't really matter what any specific person's intentions were. From this perspective, remedying institutional racism does not involve changing individuals' racist intentions as much as it involves restructuring institutional practices in order to increase equality of opportunity. (p. 102)

Increasing "equality of oppontunity" is the primary motivator behind proponents of affirmative action in college of admissions - without it, the numbers consistent with the racial bias and job applicant study mentioned above will persist unabated.

The fourth and final justification of preferential treatment in college admissions is its capacity to address the noed for diversity on college campuses. Cohen (1998) maintains that such a policy provides undisputed benefits for the leaming communities within higher education. Racial and ethnic diversity can no longer be marginalized as factors of liability and potential campus unrest. Through exchange with other perspectives from other cultures and racial backgrounds, there is an enrichment and increase in the knowledge base of the academic community uniquely afforded through diversity (pp. 280-284). His research verifies that by opening the door to a greater degree of diversity among the student body, the result is an enhancement of the overall quality of academic perfomance and competition for 


\section{Ethnic Studies Review Volume 30: 1\&2}

all involved (pp. 270-272). Based on a recent national survey, this is the exact same sentiment among the majority of faculty as well (Chang, Witt, Jones, and Hakuta, 2003, pp. 142-145).

TuSmith and Reddy (2002) confirm this position by concluding that ample diversity on a college campus is imperative, in that, for "many young people in the U.S., college is the first place they encounter people of different racial groups ... [considering too that] it may also be the first time they seriously question the beliefs that their parents have taught them" ( $p$. 127). Constituting a key instrument and vehicle to "challenge structural racism ... perhaps the best venue for this re-education is the college classroom" (p.138).

In conclusion, the compelling need for affimative action is college admissions is founfold: 1) it opens the door to financial opportunity for people of color; 2) it addresses the past wrongs of racial discrimination; 3) it takes a proactive stance against institutionalized racism; and 4) it enhances the campus diversity and thereby enriches the leaming communities within higher education.

\section{Affimative Action in College Admissions: The Compelling Waming From Critical Race Theory}

The basic tenets and principles of critical race theory (CRT) provide a theoretical model and framework to examine and analyze the viability of affimative action in college admissions. While the need for such a policy is indeed compelling, it seems beneficial to implement and overlay a tool for analysis and scrutiny. This theory, which initially surfaced in the mid-1970s, attempts to address the subtler forms of racism that had come to gradually overtake the gains of the 1950s and 1960 s civil rights movement. Using the context of race, racism, and power, CRT diagnoses the dynamics of today's race relations from six different angles, later to be explained(Delgado, 1995, pp. xiii-xv).

For the sake of background, CRT places the historical unfolding of race relations in the United States in the sociological context of privilege, power, and systematized inequality. No clearer picture of this can be seen as in the history of the African American pursuit of dignity, equity, and self-determination where the two dehumanizing institutions of slavery and segregation becarne deeply embedded and entrenched into the fibers of our nation. Both institutions roquired a social revolution and widespread bloodshed to undo their outward practice and free license of black subordination (Delgado, 1995, pp.75-82).

Yet for African Americans, the quest and struggle for equality is far from over. The gains of the civil rights movement of the 1950s and 1960s have not only ebbed (and in some areas been reversed) but has also served as a superficial panacea and false sense of amival in the minds of many white Americans, especially white liberals. As a result, a gnawing discrepancy, somewhat submerged and oftentimes disregarded, exists between whites and blacks when it comes to assessing the progress and status of racial equality in the United States. No greater evidence of this is the ongoing contention and hostility over the issue of affimative action in college admissions. Why is it that most people of color believe that our 
society contains much more racism than white Americans do? What accounts for this difference? This is where CRT's analytical model comes into function (Delgado and Stefancic, 2001,pp. 2-11).

Critical race theory (CRT) sprang up in the mid-1970s in response to the slowing and even backward trend of racial equity which soon followed the historical progresses of the 1950s and 1960s civil rights movement. By the late 1980s, following a coming to mind of various scholars, activists, lawyers, and writers, CRT was crystallized and established as a theoretical response to assess and analyze the issue of race in America from a new perspective, outside of the previous and inadequate conventional approach. Drawing from the insights of two previous movements, critical legal studies and radical feminism, CRT attempts to diagnose the racial dilemma in our society through the lenses of six basic tenets:

1) that racism is not sporadic but an ordinary, everyday matter in America;

2) that the majority of past remedics by whites have been elite interest-centered in nature;

3) that race is a social construct, a social fabrication called upon as "needed,"

4) that the dominant society utilizes and manipulates the impressions of various races to serve its pumposes at the present;

5) that each race has its own origins and constantly evolving histories, resulting in overlapping and conflicting identities and loyalties; and,

6) that only people of color, due to their firsthand experience, can narrate and bring their white counterparts into the perspective of the "minority."

(Delgado and Stefancic, 2001, pp. 3-4 \& 6-9)

The first waming or precaution from the angle of CRT is that race-conscious policies in college admissions fail to expose and break down the fabrication of race as a social construct. As a result, such measures only serve to reinforce the "terms and conditions" of race as basic, detemining factor of access to education and opportunity. CRT would propose that the heart of the issue is the need for a systemic change and that perhaps affimative action in college admissions is simply a "band-aid" or "temporary fix." Conceding that there are some gains through such policies as pointed out in the previous section, overall, it appears that we are probably witnessing a repeat of the cycle of gains and losses that characterized the initial phases of the 1950s and 1960s civil rights movement - the very same dynamics that brought on the need for CRT's inception.

A second waming in light of CRT pertains to what Delgado (1995) describes as the "rhetoric of innocence." This notion stems from the first basic tenet of CRT, namely, that racism is not sporadic in American society but is all-pervading and universal. The "rhetoric of innocence" based on the pleas of the "innocent white victim" springs forth from the "unconscious racism in each of us" (p. 551). Because we are unaware or unconscious of the racial bias within, the debate over affimative action only acerbates the tension, division, and contention between the races: 
The lesson of unconscious racism, however, is that the obvious advantages of state sponsored racism, the effects of which still are being reaped by whites today, are not the only basis for skewing the societal balance sheet. Even after the abolition of state racism, the cultural teachings persist. The presence and power of unconscious racism is apparent in job interviews, in social encounters, in courtrooms and conference rooms ... In our culture whites are necessarily advantaged, because blacks are presumed at the unconscious level by most as lazy, dumb, and criminally prone. Because the white person is advantaged by assumptions that consequently hurt blacks, the rhetorical appeal of the unfaimess to the 'innocent white victim' in the affirmative action contest is undermined."

(p. 558)

A third precaution is derived from CRT's third tenet which delineates the serving of white-interests as the motivating element behind changes or reforms such as affimative action in college admissions. In this sense, Delgado (1995) equates affirmative action as a "majoritarian device" to "promote their purposes, not ours" (pp. 356-357). Affirmative action re-frames the question of minority representation from the perspective and interests of the disarlvantaged and historically-oppressed to that of the advantaged and apparently-forgotten oppressor:

The system thus bases inclusion of people of color on principles of social utility, not reparations or rights. When those in power decide the goal has been accomplished, or is incapable of being reached, what logically happens? Naturally, the program stops. At best, then, affimative action serves as a homeostatic device, assuring that only a small number of women and people of color are hired or promoted. Not too many, for that would be terrifying, nor too few, for that would be destabilizing. Just the right number ... (pp. 355-356).

From this standpoint, the demands for "standards of quality" and "meritocracy" from opponents of affirmative action are mere devices of distraction or "smoke-screens," clouding over the real situation of serving and reinforcing the self-interests of those in power.

The fourth and final waming or precaution from CRT is based on its sixth tenet: the voice of color must be heard, validated, and authenticated in order for there to be genuine progress toward racial equality and equity. The problem with affirmative action in college admissions is that it poses as a gesture of concession while simultaneously snuffing out the very voice that is necessary to resolve the heart of the dilemma. As noted by Delgado and Stefancic (2001), the end result is a deeper chasm between blacks and whites. For African Americans, that troubling and nagging sense of "double consciousness" refemed to by 


\section{Finnie - Affirmative Action}

W.E.B. DuBois only intensifies, while for white Americans the feeling of frustration and despair concludes with "What else do they want?" (pp. 38-41)

Why such divergent results or stories? Why do the two fail to reconcile? Delgado and Stefancic reply: “To the first question, critical race theory answers, 'expenence.' (Derrick Bell would add, 'interest convergence' - people believe what benefits them.) To the second, it answers that empathy is in short supply" (2001, p. 41).

And without the "voice of color" the minority perspective will remain unknown and foreign to their white counterparts. In this regard, affirmative action proves to be powerless and perhaps only serves to "muddy the waters."

\section{Conclusion}

Affirmative action in college admissions points to an immediate need for equity, yet as framed by critical race theory, it also points to our tendency as Americans for a quick and easy solution that typically ends up being compromised by superficiality - whether consciously or unconsciously. In light of the evidence before us, I believe the necessity of affirmative action in college admissions cannot be disputed at this juncture in our society; nor can it be argued that such policies, in essence, are no more than mere stop-gap measures. As stated in this closing excerpt, perhaps the final and deciding factor is "commitment" and the fact that, as a nation, if we don't have enough of it, we won't go that far down the road to equality and equity without it:

There is still an urgent need for more focused study of what policies and efforts are necessary to eradicate the effects of discrimination and to create truly equal opportunity. There must be broader commitment to this sort of study in order both to understand better the significance of racism's legacy and to establish effective and sustainable remedies. We believe that higher education, in which there is a tradition of focused dialogue, debate, and research, is the ideal setting for initiating and sustaining work in this area. (Chang,Witt, Jones, and Hakuta, 2003, p.17).

\section{References}

Bok, D. \& Bowen, W. G. (1998). The shape of the river: Long-term consequences of considering race in college and university admissions. Princeton, NJ: Princeton University Press.

Chang, M.J., Witt, D., Jones, J. \& Hakuta, K. Compelling interest: examining the evidence in colleges and universities. (2003). Stanford, CA: Stanford University Press. 


\section{Ethnic Studies Review Volume 30: 1\&2}

Cohen, M.N. (1998). Culture of intolerance: Chauvinism, class, and racism in the United States. New Haven, CT: Yale University Press.

Delgado, R. (Ed.). (1995). Critical race theory: The cutting edge. Philadelphia: Temple University Press.

Delgado, R. \& Stefancic, J. (2001). Critical race theory: An introduction. New York: New York University Press.

Eastland, T. (1996). Ending affirmative action. New York: Harper Collins.

Feinberg, W. (1998). On higher ground: Education and the case for affimative action. New York: Teachers College Press.

Garcia, M. (1997). Affimative action's testament of hope: Strategies for a new era in higher education. New York: State University of New York Press.

Laser, W. (1999). American politics: The enduring constitution. ( $2^{\text {nd }}$ ed.). Boston: Houghton Mifflin.

Lowe, E. Y, Jr. (Ed.). (1999). Promise and dilemma: Perspectives on racial diversity and higher education. Princeton, NJ: Princeton University Press.

Meier, K.J., Stewart, J., Jr, \& England, R.E. (1989). Race, class, and education: The politics of second-generation discrimination. Madison, WI:The University of Wisconsin Press.

TuSmith, B. \& Reddy, M.T. (Eds.). (2002). Race in the college classroom: Pedagogy and politics. New Brunswick, NJ: Rutgers University Press.

Zelnick, B. (1996). Backfire: A reporter's look at affirmative action. Washington, D.C.: Regnery. 